\title{
REVIEW
}

\section{The therapeutic effect of mesenchymal stem cell transplantation in experimental autoimmune encephalomyelitis is mediated by peripheral and central mechanisms}

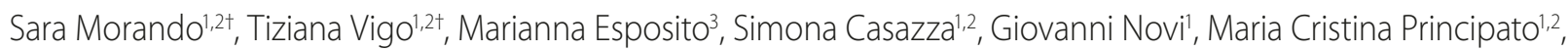 \\ Roberto Furlan ${ }^{3}$ and Antonio Uccelli, ${ }^{1,2,4}$
}

\begin{abstract}
Stem cells are currently seen as a treatment for tissue regeneration in neurological diseases such as multiple sclerosis, anticipating that they integrate and differentiate into neural cells. Mesenchymal stem cells (MSCs), a subset of adult progenitor cells, differentiate into cells of the mesodermal lineage but also, under certain experimental circumstances, into cells of the neuronal and glial lineage. Their clinical development, however, has been significantly boosted by the demonstration that MSCs display significant therapeutic plasticity mainly occurring through bystander mechanisms. These features have been exploited in the effective treatment of experimental autoimmune encephalomyelitis, an animal model of multiple sclerosis where the inhibition of the autoimmune response resulted in a significant amelioration of disease and decrease of demyelination, immune infiltrates and axonal loss. Surprisingly, these effects do not require MSCs to engraft in the central nervous system but depend on the cells' ability to inhibit pathogenic immune responses both in the periphery and inside the central nervous system and to release neuroprotective and pro-oligodendrogenic molecules favoring tissue repair. These results paved the road for the utilization of MSCs for the treatment of multiple sclerosis.
\end{abstract}

${ }^{+}$Contributed equally

*Correspondence: auccelli@neurologia.unige.it

'Department of Neurosciences Ophthalmology and Genetics, University of Genoa, Via De Toni 5, 16132 Genoa, Italy

Full list of author information is available at the end of the article

\section{Mesenchymal stem cells are stromal progenitors of the mesodermal lineage}

Mesenchymal stem cells (MSCs) are a heterogeneous subset of stromal stem cells that can be isolated from many adult connective tissues. The cells grow as plasticadherent fibroblast-like cells that proliferate in vitro, maintaining pluripotency after prolonged culture. Under appropriate stimulus, MSCs can differentiate in vitro and in vivo into cells of the mesodermal lineage, such as bone, fat and cartilage cells.

MSCs have mainly been characterized after isolation from the bone marrow, where they are likely to represent the precursor cells for stromal tissue in close physical association with hematopoietic stem cells involved in hematopoiesis and maintenance of the homeostasis of the hematopoietic stem cell niche [1]. In the bone marrow the existence of a population of neural-crestderived stem cells was also shown, thus providing an explanation for the reported ability of bone-marrowderived stem cells to also generate, to some extent, neural cells [2].

Despite evidence showing that MSCs can transdifferentiate into multiple cell types in vitro and in vivo, the real contribution of MSCs to tissue repair - through significant engraftment and differentiation into biologically and functionally relevant tissue-specific cell types is still elusive [3]. In the bone marrow, MSCs provide a sheltering microenvironment contributing to the preservation of hematopoietic stem cells by shielding them from differentiation and apoptotic stimuli and regulating their quiescence, proliferation and differentiation. Owing to their ability to support hematopoiesis, MSCs were first utilized to enhance immune reconstitution when transplanted together with hematopoietic stem cells. The translation of the capacity of MSCs to differentiate into other tissues was first exploited for reparative purposes, for example, in bone and heart diseases. The observation 
that bone-marrow-derived MSCs suppressed T-cell proliferation in vitro [4] and in vivo [5], however, unexpectedly drove attention to their exploitation for the treatment of immune-mediated diseases; for example, in those diseases where their ability of modulating the immune response could combine with the ability to integrate into damaged tissues and foster repair. Experimental autoimmune encephalomyelitis (EAE), a model for multiple sclerosis, has been the first experimental autoimmune disease successfully treated with MSCs [6].

\section{Experimental autoimmune encephalomyelitis is an example of immune-mediated disease}

EAE can be actively induced in susceptible inbred rodents by immunization with different neural antigens mainly derived from myelin, including myelin basic protein, proteolipid protein (PLP) and myelin oligodendrocyte protein (MOG) in complete Freud's adjuvant. Disease induction with PLP in SJL mice, and likewise MOG in C57BL/6 mice, requires the use of pertussis toxin that facilitates immune cell entry into the central nervous system (CNS) and contributes to T-cell tolerance breaking. EAE can be also induced in naïve mice by the intravenous passive transfer of encephalitogenic myelinspecific $\mathrm{T}$ cells. In fact, EAE is considered a prototypical MHC class-II-restricted CD4 ${ }^{+}$T-cell-mediated disease. During the induction phase, myelin-reactive CD4 ${ }^{+} \mathrm{T}$ cells are primed and expanded in the peripheral lymphoid organs. The effector phase involves migration of activated myelin-specific $\mathrm{T}$ cells to the CNS, where they cross the blood-brain barrier and require myelin peptides presented by local antigen-presenting cells and dendritic cells for full reactivation [7].

Several lines of evidence indicate that many subsets of $\mathrm{T}$ cells play different roles in the onset, maintenance and recovery of EAE, T-helper-type 17 cells and regulatory $\mathrm{T}$ cells being among the main contributors to the final outcome [8]. Not only $\mathrm{T}$ cells but also B cells producing demyelinating antibodies and macrophages are key effector cells in EAE pathogenesis. Typical EAE lesions resemble patterns of demyelination, inflammatory cell perivascular infiltrates, reactive microgliosis and astrocytosis, observed in multiple sclerosis lesions [9].

\section{Systemic effect of the intravenous delivery of mesenchymal stem cells in experimental autoimmune encephalomyelitis}

In the study by Zappia and colleagues we demonstrated that intravenous injection of syngeneic MSCs into C57BL/6 mice immunized with peptide 35 to 55 of MOG significantly improved the clinical severity of EAE, in parallel decreasing CNS inflammation and demyelination [6]. More importantly, we demonstrated that one injection of MSCs at disease onset or at the peak of disease suffices to induce peripheral tolerance, as demonstrated by the inability of $\mathrm{T}$ cells isolated from lymph nodes of MSC-treated mice, but not from control animals, to proliferate when stimulated with the immunizing antigen MOG. We also observed a dosedependent effect that reached maximum efficacy and negligible mortality at the dose of $1 \times 10^{6}$ MSCs. No clinical effect was observed when MSCs were infused during the chronic phase of EAE, suggesting that multiple injections may not provide further advantages if permanent tissue damage has occurred [6]. In another study, Zhang and colleagues demonstrated that intravenous administration of human MSCs could improve the clinical course of PLP-induced EAE in SJL mice through some level of engraftment in the CNS and subsequent release of neurotrophic factors promoting oligodendrogenesis [10]. These results highlighted that MSCs can cross MHC boundaries and exert their therapeutic effect also in the CNS, regardless of a very limited engraftment. Following these pioneer works, in the last years several studies have focused on the mechanisms underlying the therapeutic effect of MSC transplantation on EAE.

The concept that MSCs ameliorate EAE through the induction of peripheral immune tolerance was further nourished by the demonstration that intravenous administration of allogeneic MSCs in PLP-immunized mice inhibits the production of myelin-specific antibodies compared with controls [11]. In addition, the exposition of encephalitogenic T cells to MSCs in vitro significantly decreases their ability to passively transfer EAE to healthy syngeneic mice [11]. Many other studies have confirmed that MSCs can modulate the peripheral immune response to myelin antigens [12-19]. These in vivo results have been corroborated by detailed in vitro studies dissecting the mechanisms of action of MSCs on T lymphocytes, B lymphocytes, dendritic cells, natural killer cells and other immune cells [20].

\section{Mesenchymal stem cells are neuroprotective}

It is important to underline that effects of MSCs on EAE are not exclusively due to their immunomodulatory activity, as many groups have shown that MSCs can also protect neurons and spare axons with no or very limited evidence of engraftment and/or transdifferentiation into neural cells $[11-13,15,16,21]$. These findings posed the question of whether the observed neuroprotection in EAE is due to the peripheral effects suppressing the immune response that damages myelin or to a direct protective and reparative activity that follows their engraftment in the CNS.

Several lines of evidence suggest that, somehow, MSCs have a direct effect on neural cells. They have been shown to enhance remyelination in vivo $[15,16]$, provide in vitro 


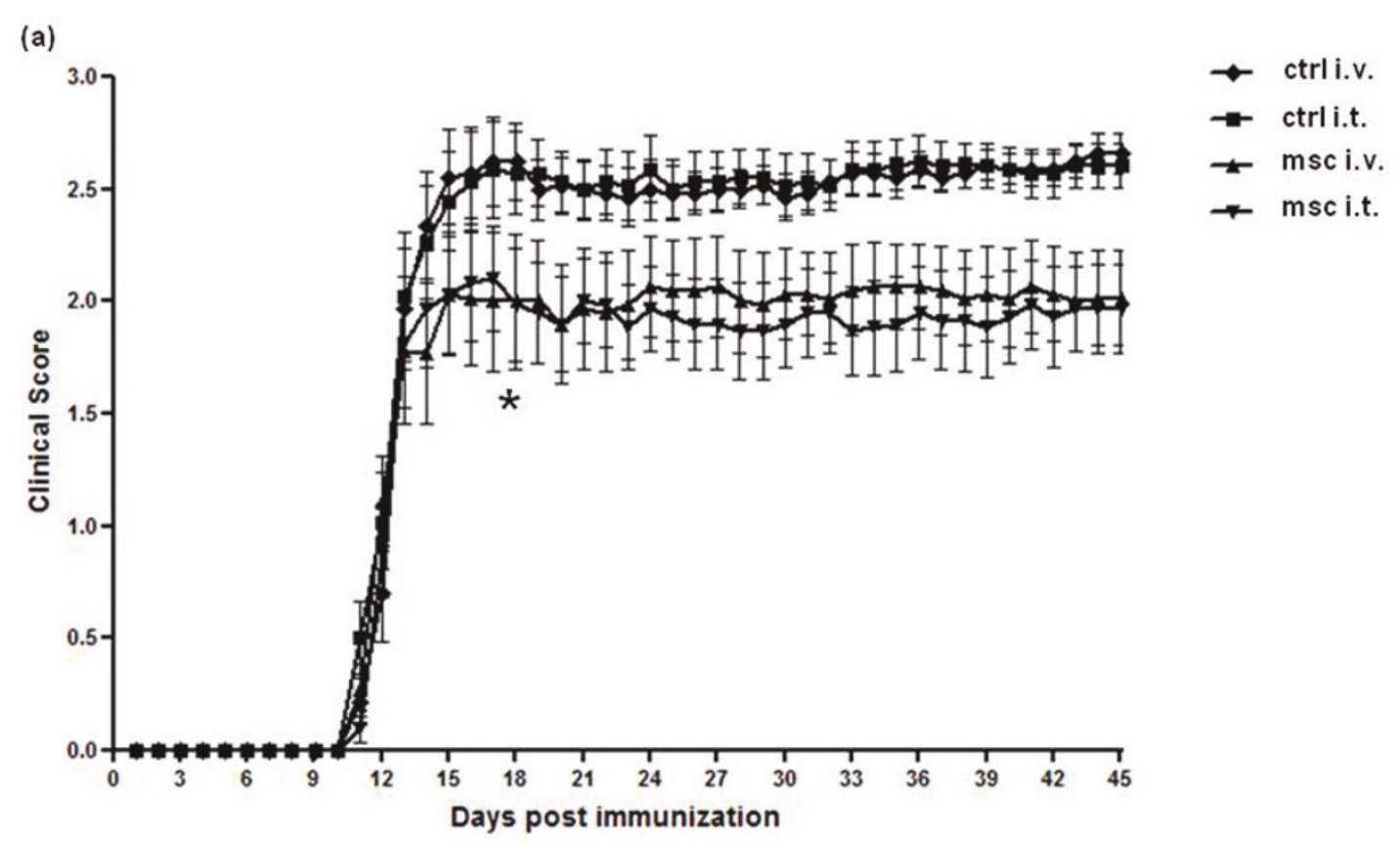

(b)
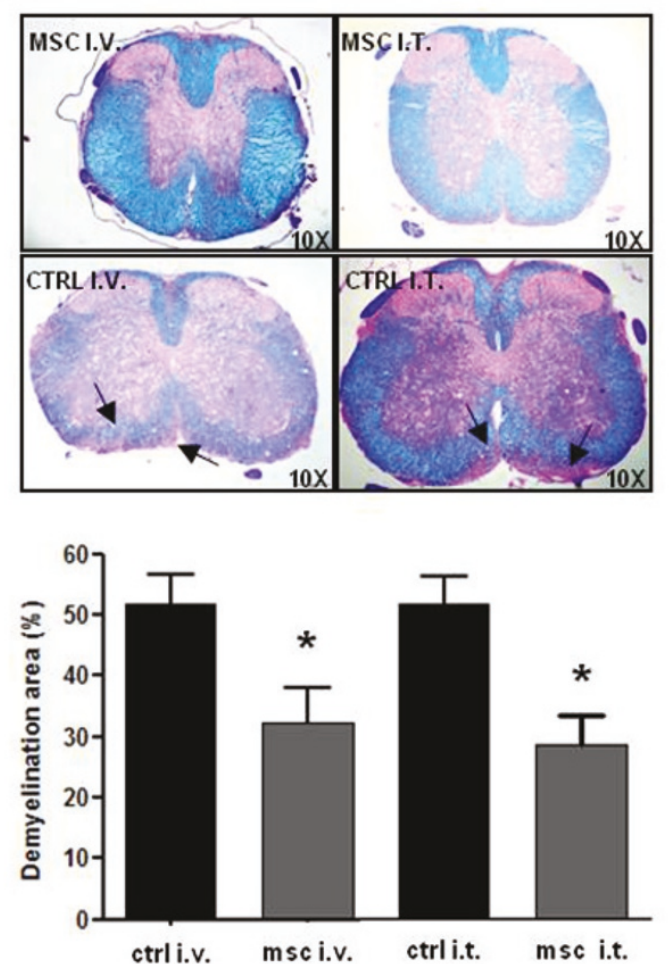

(c)

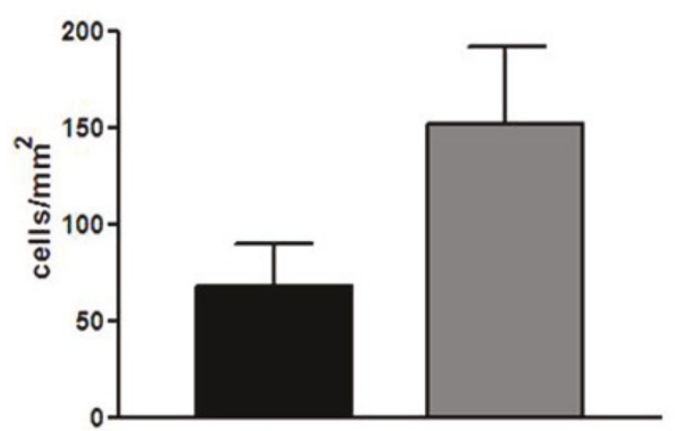

i.v.

i.t.

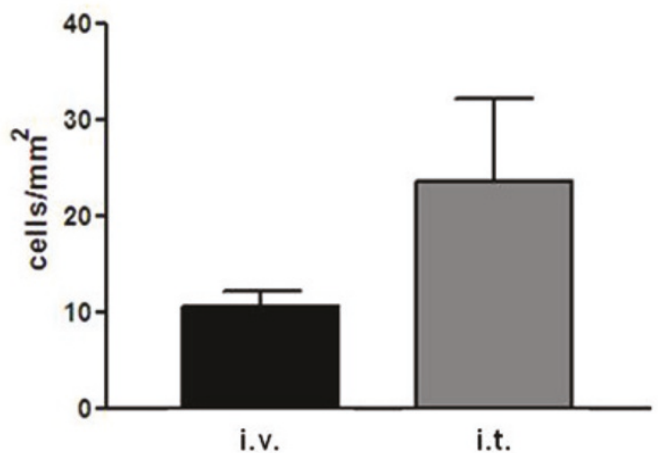

Figure 1. Local mesenchymal stem cell administration does not provide significant advantage compared with systemic infusion. (a) Clinical course of peptide 33 to 55 of myelin oligodendrocyte glycoprotein-induced experimental autoimmune encephalomyelitis (EAE) in C57Bl6 mice after intrathechal (i.t.) or intravenous (i.v.) mesenchymal stem cell (MSC) injection. Arrow, day of injection. * $P \leq 0.05$ Mann-Whitney $U$ test. (b) Analysis of demyelination in the spinal cord of treated mice; $5 \mu \mathrm{m}$ sections were stained with Luxol Fast Blue and the demyelinated area was expressed as a percentage of the total surface area. ${ }^{*} P \leq 0.01$ Mann-Whitney $U$ test. (c) Counts of luciferase-labeled MSCs in the central nervous system (CNS) of EAE-affected mice. Luciferase-positive MSCs were detected using a rabbit anti-luciferase monoclonal antibody (Alexa Fluor 488-conjugated) after 24 hours and 40 days from intravenous and intratechal injection. Six CNS tissue sections per mouse were analyzed and in each section the number of positive cells was reported as the number of positive elements $/ \mathrm{mm}^{2}$. 
Table 1. Clinical features of experimental autoimmune encephalomyelitis-affected mice

\begin{tabular}{lcccc}
\hline & $\begin{array}{c}\text { Disease } \\
\text { incidence }\end{array}$ & $\begin{array}{c}\text { Disease onset, } \\
\text { days after immunization }\end{array}$ & $\begin{array}{c}\text { Mean maximum } \\
\text { neurologic score }\end{array}$ & $\begin{array}{c}\text { Cumulative } \\
\text { disease score }\end{array}$ \\
\hline EAE control i.v. & $14 / 14(100 \%)$ & $12 \pm 0.8$ & $3 \pm 0.5$ & $84.4 \pm 13$ \\
EAE + MSCs i.v. & $14 / 15(93.4 \%)$ & $11.5 \pm 0.5$ & $2.5 \pm 0.9$ & $67.6 \pm 28.7^{*}$ \\
EAE control i.t. & $14 / 14(100 \%)$ & $11.6 \pm 0.6$ & $3 \pm 0.5$ & $85.2 \pm 15.3$ \\
EAE + MSCs i.t. & $14 / 15(93.4 \%)$ & $12.3 \pm 1$ & $2.4 \pm 0.7^{*}$ & $63.7 \pm 25.7^{*}$ \\
\hline
\end{tabular}

Data presented as $n$ / total (\%) or mean \pm standard deviation. EAE, experimental autoimmune encephalomyelitis; i.t., intrathecally; i.v., intravenously; MSC, mesenchymal stem cell. * $P \leq 0.05$ (Student's $t$ test).

soluble cues that influence fate determination of neural cells $[16,22]$, display a potent antioxidant effect in vivo $[23,24]$ and display a neuroprotective effect [25] mediated by the release of antiapoptotic molecules in vitro [26] and in vivo [27]. These neuroprotective effects may well explain the remarkable effect obtained with the administration of MSCs in experimental models of stroke [28] and spinal cord injury [29]. There is uncertainty, however, regarding the ability of MSCs to colonize the CNS after peripheral delivery due to their scarce ability to pass the lung filter following intravenous administration [30] and due to the lack of reliable labels or definitive markers for MSCs [31].

Irrespective of these aspects, the current view suggests that MSCs may exert their neuroprotective effect at distance through the release of trophic molecules, possibly affecting microglia activation [27] and inducing local neurogenesis $[15,16,32]$.

\section{Does local administration provide significant advantage compared with systemic infusion?}

To enhance the possibility for MSCs to engraft in the CNS and provide optimal therapeutic effects locally, Kassis and colleagues demonstrated, following intraventricular injection of MSCs, the expression of neural markers by a few transplanted labeled cells mainly in the proximity of inflammatory lesions - suggesting that some level of transdifferentiation was achieved [12]. Similarly, Barhum and colleagues showed that intraventricular administration in vitro of MSCs modified to produce neurotrophins successfully attenuated EAE [19].

We therefore evaluated whether local injection of a high number of MSCs may provide some advantage over intravenous systemic administration by comparing two different routes of cell delivery in $\mathrm{C} 57 \mathrm{Bl} / 6$ mice following immunization with the myelin antigen, peptide 35 to 55 of MOG. The intratechal delivery of $1 \times 10^{6} \mathrm{MSCs}$ at the onset of the first clinical symptoms (around day 10) resulted in a significant amelioration of EAE compared with intratechally PBS-injected animals. No significant difference was observed, however, when we compared the clinical course of mice intravenously injected with those treated intratechally (Figure 1 and Table 1). No significant difference was also observed when the extent of spinal cord demyelinating lesions was compared (Figure 1). As expected, the number of Luciferasetransfected MSCs, detected after 24 hours in the CNS of intratechally injected mice, was higher than in those where MSCs were delivered intravenously. After 40 days, however, the number of Luciferase-positive cells was clearly diminished with no statistical difference between the two groups (Figure 1). These results favor the current hypothesis that MSCs act by different mechanisms, mainly paracrinally on cells both at a distance and at the site of tissue damage, without the requirement of longterm engraftment [33].

\section{Intravenous injection of mesenchymal stem cells also modulates the immune response in the CNS}

A major issue still unsolved by the above-described studies was whether intravenously injected MSCs could also impact the immune response inside the CNS. It is well known that, following intravenous administration, MSCs inhibit infiltration of $\mathrm{T}$ cells and macrophages in mice with EAE [6]. These results, however, are likely to be an effect of the cells' tolerogenic ability exerted in the periphery on encephalitogenic $\mathrm{T}$ cells, as demonstrated by the inhibition of EAE following passive transfer of myelin-specific $T$ cells [11].

To address this question we isolated $\mathrm{T}$ cells infiltrating the brain of EAE-affected mice treated either intravenously or intratechally with MSCs and we measured by intracellular flow cytometry and real-time PCR the expression of the transcription factor FOXP3, a specific marker of regulatory $\mathrm{T}$ cells previously demonstrated to be expanded in the lymphoid organs of mice with collagen-induced arthritis treated with MSCs [34]. We observed not only that the intratechal delivery of MSCs induced an expansion of FoxP3 ${ }^{+} \mathrm{T}$ cells in the brain of EAE-affected mice compared with controls, but also that a similar result was observed in intravenously injected mice (Figure 2). Such a result probably depends on increased recruitment of this subset from the peripheral blood. To our surprise we observed, in the T cells isolated from the brain of both groups of MSC-treated mice compared with controls, an increase in the expression of 

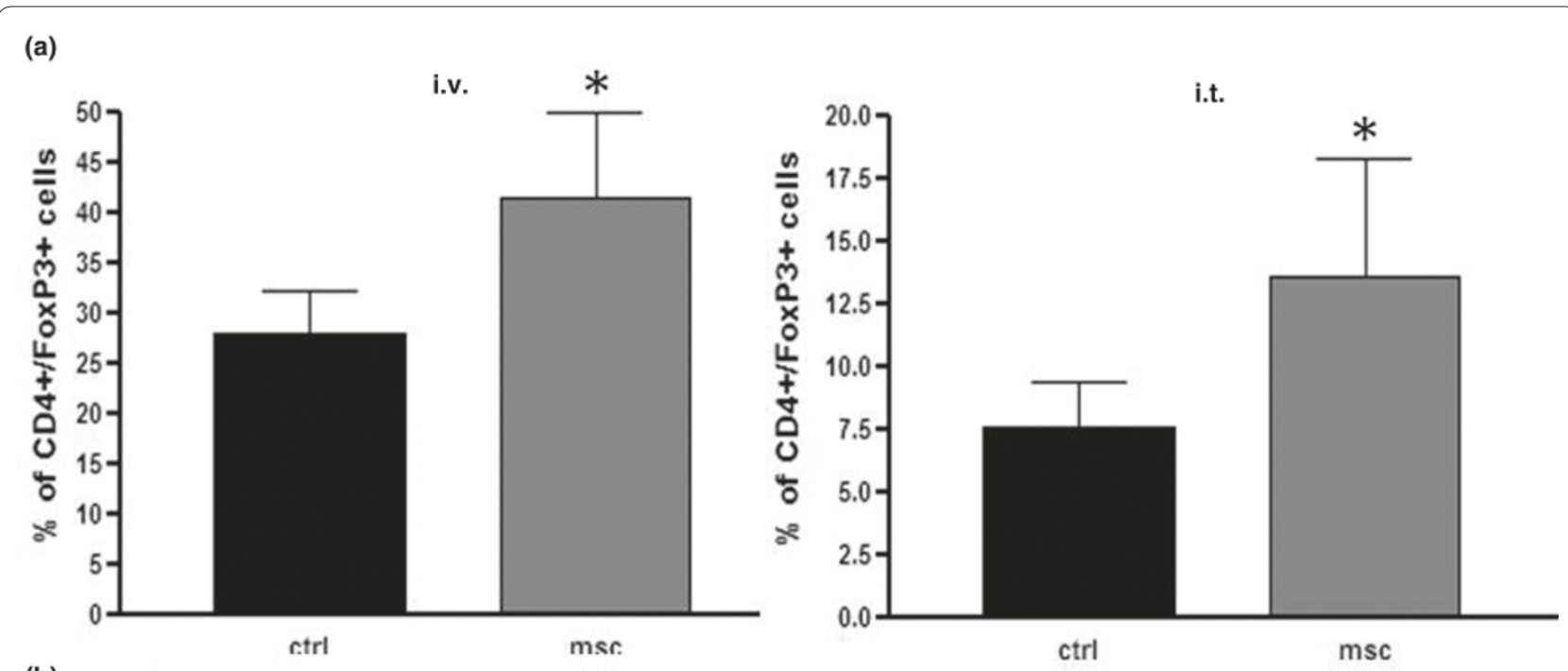

(b)
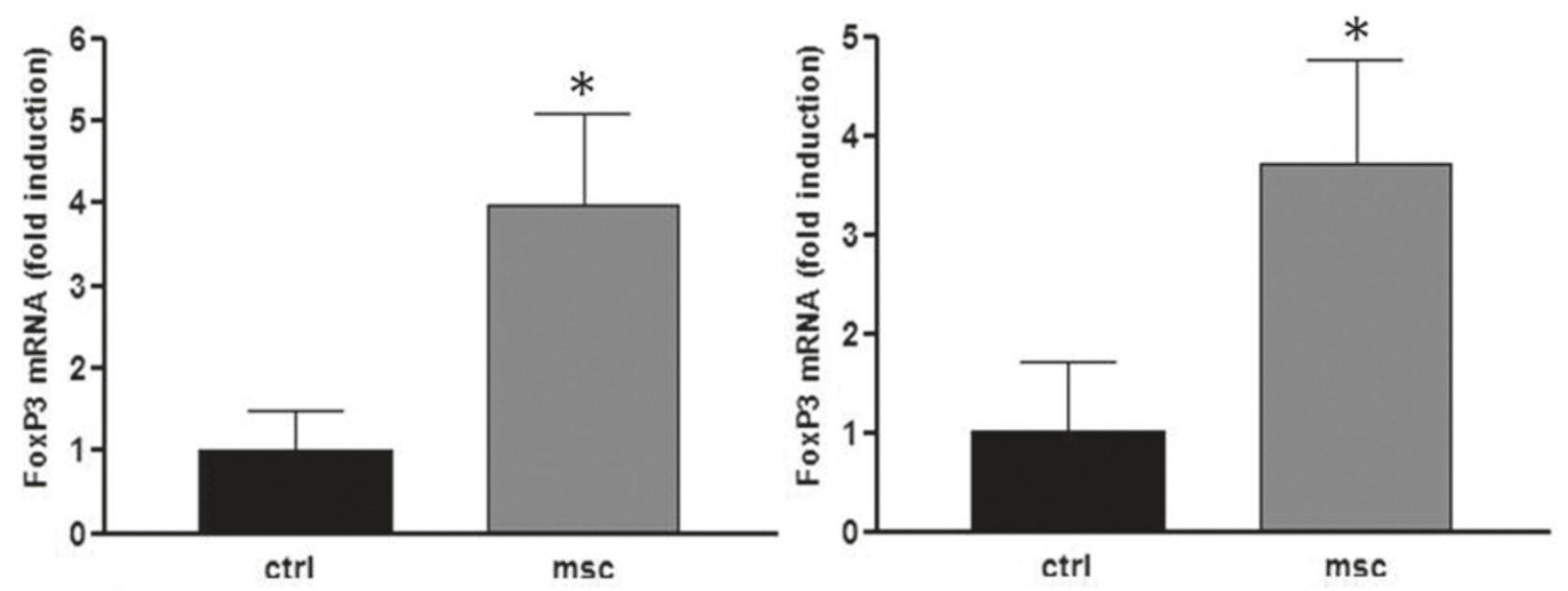

(c)
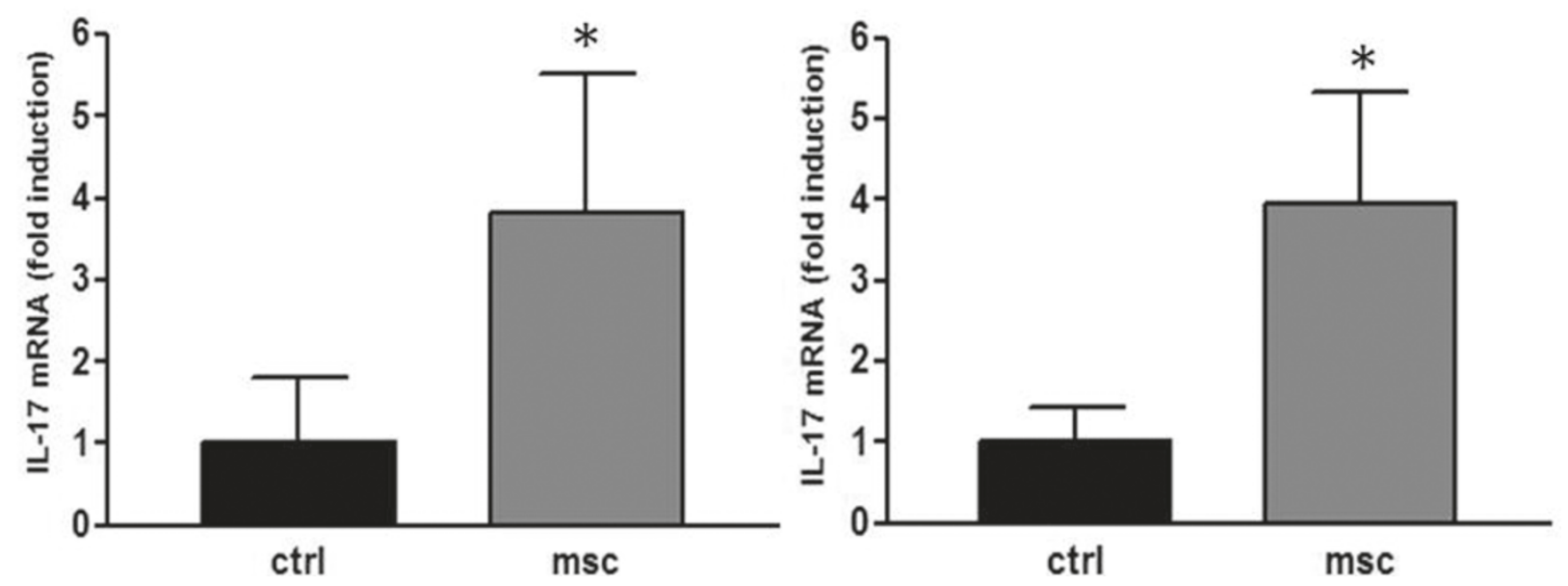

Figure 2. Intratechal and intravenous injection of mesenchymal stem cells modulates immune response in central nervous system.

Expression of FoxP3 in T cells infiltrating the central nervous system of experimental autoimmune encephalomyelitis affected mice at the peak of disease: (a) at protein level, evaluated by intracellular flow cytometry (FACSCanto Il; BD Bioscience, Buccinasco, Milan, Italy); and (b) at mRNA level, evaluated by real-time PCR using a LightCycler ${ }^{\oplus} 80$ (Roche Applied Science, Indianapolis, IN, USA). (c) IL-17 mRNA expression from infiltrating T cells, analyzed by real-time PCR. ${ }^{*} P \leq 0.05$ Mann-Whitney U test. i.v., intravenous; i.t. intrathecal. 
IL-17, a cytokine that plays an important role in the pathogenesis of autoimmune diseases (Figure 2). These results may be explained by the recent demonstration that MSCs can induce T-helper-type 17 cells to acquire a regulatory phenotype [35], and may also clarify the observation that human MSCs were shown to increase Thelper-type 17 responses in vitro [36].

\section{Conclusions}

Overall, many studies have confirmed that MSCs, either from syngenic or xenogeneic sources, are effective in the treatment of EAE and dissected their mechanisms of action, probably in a much deeper fashion than in any other experimental disease. The results discussed in the present article demonstrate that MSCs can repair neural tissues as they display a broad therapeutic activity that acts both on immune and neural cells but feebly involves their transdifferentiation. Interestingly, despite a limited ability to engraft in the nervous system, MSCs can clearly modulate the immune response not only in the peripheral lymphoid organs [6] but also within the CNS.

Based on these studies and the available clinical experience obtained in several human conditions, MSCs can be considered an appealing therapeutic option for multiple sclerosis individuals with ongoing inflammatory disease refractory to conventional therapies $[37,38]$.

This article is part of a review series on Immunology and stem cells, edited by Christian Jorgensen. Other articles in the series can be found online at http://stemcellres.com/series/immunology

\section{Abbreviations}

CNS, central nervous system; EAE, experimental autoimmune encephalomyelitis; IL, interleukin; MHC, major histocompatibility complex; MOG, myelin oligodendrocyte glycoprotein; MSC, mesenchymal stem cell; PBS, phosphate-buffered saline; PCR, polymerase chain reaction; PLP, proteolipid protein.

\section{Competing interests}

The authors declare that they have no competing interests.

\section{Acknowledgements}

Some of the studies discussed in this article were supported by grants from the Fondazione Italiana Sclerosi Multipla, the Italian Ministry of Health (Ricerca Finalizzata), the Italian Ministry of the University and Scientific Research (MIURPRIN), the Progetto LIMONTE, and the Fondazione CARIGE. The authors thank Tiziana Ferrando for technical assistance on histological analysis. The skillful secretarial assistance of Tiziana Poggio is gratefully acknowledged.

\section{Author details}

'Department of Neurosciences Ophthalmology and Genetics, University of Genoa, Via De Toni 5, 16132 Genoa, Italy. ${ }^{2}$ Advanced Biotechnology Center, Largo R. Benzi 10, 16132, Genoa, Italy. ${ }^{3}$ Clinical Neuroimmunology Unit, Institute of Experimental Neurology, Division of Neuroscience, San Raffaele Scientific Institute, Via Olgettina 58, 20132, Milan, Italy. ${ }^{4}$ Center of Excellence for Biomedical Research, University of Genoa, Largo R. Benzi 10, 16132, Genoa, Italy.

Published: 26 January 2012

\section{References}

1. Mendez-Ferrer S, Michurina TV, Ferraro F, Mazloom AR, Macarthur BD, Lira SA, Scadden DT, Ma'ayan A, Enikolopov GN, Frenette PS: Mesenchymal and haematopoietic stem cells form a unique bone marrow niche. Nature 2010, 466:829-834

2. Nagoshi N, Shibata S, Kubota Y, Nakamura M, Nagai Y, Satoh E, Morikawa S, Okada Y, Mabuchi Y, Katoh H, Okada S, Fukuda K, Suda T, Matsuzaki Y, Toyama Y, Okano H: Ontogeny and multipotency of neural crest-derived stem cells in mouse bone marrow, dorsal root ganglia, and whisker pad. Cell Stem Cell 2008, 2:392-403.

3. Phinney DG, Prockop DJ: Concise review: mesenchymal stem/multipotent stromal cells: the state of transdifferentiation and modes of tissue repair current views. Stem Cells 2007, 25:2896-2902.

4. Di Nicola M, Carlo-Stella C, Magni M, Milanesi M, Longoni PD, Matteucci P, Grisanti S, Gianni AM: Human bone marrow stromal cells suppress T-lymphocyte proliferation induced by cellular or nonspecific mitogenic stimuli. Blood 2002, 99:3838-3843.

5. Bartholomew A, Sturgeon C, Siatskas M, Ferrer K, Mclntosh K, Patil S, Hardy W, Devine S, Ucker D, Deans R, Moseley A, Hoffman R: Mesenchymal stem cells suppress lymphocyte proliferation in vitro and prolong skin graft survival in vivo. Exp Hematol 2002, 30:42-48.

6. Zappia E, Casazza S, Pedemonte E, Benvenuto F, Bonanni I, Gerdoni E, Giunti D, Ceravolo A, Cazzanti F, Frassoni F, Mancardi G, Uccelli A: Mesenchyma stem cells ameliorate experimental autoimmune encephalomyelitis inducing T cell anergy. Blood 2005, 106:1755-1761.

7. Miller SD, Karpus WJ, Davidson TS: Experimental autoimmune encephalomyelitis in the mouse. Current Protoc Immunol 2010, chapter 15:unit 15.1 .

8. Steinman $L$ : A brief history of $T(H) 17$, the first major revision in the $T(H) 1 /$ $\mathrm{T}(\mathrm{H}) 2$ hypothesis of T cell-mediated tissue damage. Nat Med 2007, 13:139-145.

9. Gold R, Linington C, Lassmann $\mathrm{H}$ : Understanding pathogenesis and therapy of multiple sclerosis via animal models: 70 years of merits and culprits in experimental autoimmune encephalomyelitis research. Brain 2006, 129:1953-1971.

10. Zhang J, Li Y, Chen J, Cui Y, Lu M, Elias SB, Mitchell JB, Hammill L, Vanguri P, Chopp M: Human bone marrow stromal cell treatment improves neurological functional recovery in EAE mice. Exp Neuro/ 2005, 195:16-26.

11. Gerdoni E, Gallo B, Casazza S, Musio S, Bonanni I, Pedemonte E, Mantegazza R, Frassoni F, Mancardi G, Pedotti R, Uccelli A: Mesenchymal stem cells effectively modulate pathogenic immune response in experimental autoimmune encephalomyelitis. Ann Neurol 2007, 61:219-227.

12. Kassis I, Grigoriadis N, Gowda-Kurkalli B, Mizrachi-Kol R, Ben-Hur T, Slavin S, Abramsky O, Karussis D: Neuroprotection and immunomodulation with mesenchymal stem cells in chronic experimental autoimmune encephalomyelitis. Arch Neurol 2008, 65:753-761.

13. Gordon D, Pavlovska G, Glover CP, Uney JB, Wraith D, Scolding NJ: Human mesenchymal stem cells abrogate experimental allergic encephalomyelitis after intraperitoneal injection, and with sparse CNS infiltration. Neurosci Lett 2008, 448:71-73.

14. Rafei M, Campeau PM, Aguilar-Mahecha A, Buchanan M, Williams P, Birman E, Yuan S, Young YK, Boivin MN, Forner K, Basik M, Galipeau J: Mesenchymal stromal cells ameliorate experimental autoimmune encephalomyelitis by inhibiting CD4 Th17 T cells in a CC chemokine ligand 2-dependent manner. J Immuno/ 2009, 182:5994-6002.

15. Constantin G, Marconi S, Rossi B, Angiari S, Calderan L, Anghileri E, Gini B, Bach SD, Martinello M, Bifari F, Galiè M, Turano E, Budui S, Sbarbati A Krampera M, Bonetti B: Adipose-derived mesenchymal stem cells ameliorate chronic experimental autoimmune encephalomyelitis. Stem Cells 2009, 27:2624-2635.

16. Bai L, Lennon DP, Eaton V, Maier K, Caplan Al, Miller SD, Miller RH: Human bone marrow-derived mesenchymal stem cells induce Th2-polarized immune response and promote endogenous repair in animal models of multiple sclerosis. Glia 2009, 57:1192-1203.

17. Lanz TV, Opitz CA, Ho PP, Agrawal A, Lutz C, Weller M, Mellor AL, Steinman L, Wick W, Platten M: Mouse mesenchymal stem cells suppress antigenspecific TH cell immunity independent of indoleamine 2,3-dioxygenase 1 (IDO1). Stem Cells Dev 2010, 19:657-668.

18. Matysiak M, Orlowski W, Fortak-Michalska M, Jurewicz A, Selmaj K Immunoregulatory function of bone marrow mesenchymal stem cells in EAE depends on their differentiation state and secretion of $\mathrm{PGE}_{2}$. 
J Neuroimmunol 2011, 233:106-111.

19. Barhum Y, Gai-Castro S, Bahat-Stromza M, Barzilay R, Melamed E, Offen D: Intracerebroventricular transplantation of human mesenchymal stem cells induced to secrete neurotrophic factors attenuates clinical symptoms in a mouse model of multiple sclerosis. J Mol Neurosci 2010, 41:129-137.

20. Uccelli A, Moretta L, Pistoia V: Mesenchymal stem cells in health and disease. Nat Rev Immunol 2008, 8:726-736.

21. Zhang J, Li Y, Lu M, Cui Y, Chen J, Noffsinger L, Elias SB, Chopp M: Bone marrow stromal cells reduce axonal loss in experimental autoimmune encephalomyelitis mice. J Neurosci Res 2006, 84:587-595.

22. Rivera FJ, Couillard-Despres S, Pedre X, Ploetz S, Caioni M, Lois C, Bogdahn U, Aigner L: Mesenchymal stem cells instruct oligodendrogenic fate decision on adult neural stem cells. Stem Cells 2006, 24:2209-2219.

23. Lanza C, Morando S, Voci A, Canesi L, Principato MC, Serpero LD, Mancardi G, Uccelli A, Vergani L: Neuroprotective mesenchymal stem cells are endowed with a potent antioxidant effect in vivo. J Neurochem 2009, 110:1674-1684

24. Ripoll CB, Flaat M, Klopf-Eiermann J, Fisher-Perkins JM, Trygg CB, Scruggs BA McCants ML, Leonard HP, Lin AF, Zhang S, Eagle ME, Alvarez X, Li YT, Li SC, Gimble JM, Bunnell BA: Mesenchymal lineage stem cells have pronounced anti-inflammatory effects in the twitcher mouse model of Krabbe's disease. Stem Cells 2011, 29:67-77.

25. Stemberger S, Jamnig A, Stefanova N, Lepperdinger G, Reindl M, Wenning GK: Mesenchymal stem cells in a transgenic mouse model of multiple system atrophy: immunomodulation and neuroprotection. PloS One 2011, 6:e19808.

26. Kemp K, Hares K, Mallam E, Heesom KJ, Scolding N, Wilkins A: Mesenchymal stem cell-secreted superoxide dismutase promotes cerebellar neuronal survival. J Neurochem 2010, 114:1569-1580.

27. Ohtaki H, Ylostalo JH, Foraker JE, Robinson AP, Reger RL, Shioda S, Prockop DJ: Stem/progenitor cells from bone marrow decrease neuronal death in global ischemia by modulation of inflammatory/immune responses. Proc Natl Acad SciU S A 2008, 105:14638-14643.

28. Li Y, Chen J, Chen XG, Wang L, Gautam SC, Xu YX, Katakowski M, Zhang LJ, Lu M, Janakiraman N, Chopp M: Human marrow stromal cell therapy for stroke in rat: neurotrophins and functional recovery. Neurology 2002, 59:514-523.

29. Akiyama Y, Radtke C, Honmou O, Kocsis JD: Remyelination of the spinal cord following intravenous delivery of bone marrow cells. Glia 2002, 39:229-236.
30. Lee RH, Pulin AA, Seo MJ, Kota DJ, Ylostalo J, Larson BL, Semprun-Prieto L, Delafontaine P, Prockop DJ: Intravenous hMSCs improve myocardial infarction in mice because cells embolized in lung are activated to secrete the anti-inflammatory protein TSG-6. Cell Stem Cell 2009, 5:54-63.

31. Karp JM, Leng Teo GS: Mesenchymal stem cell homing: the devil is in the details. Cell Stem Cell 2009, 4:206-216.

32. Munoz JR, Stoutenger BR, Robinson AP, Spees JL, Prockop DJ: Human stem/ progenitor cells from bone marrow promote neurogenesis of endogenous neural stem cells in the hippocampus of mice. Proc Natl Acad SciU SA 2005, 102:18171-18176

33. Uccelli A, Prockop DJ: Why should mesenchymal stem cells (MSCs) cure autoimmune diseases? Current Opin Immunol 2010, 22:768-774.

34. Augello A, Tasso R, Negrini SM, Cancedda R, Pennesi G: Cell therapy using allogeneic bone marrow mesenchymal stem cells prevents tissue damage in collagen-induced arthritis. Arthritis Rheum 2007, 56:1175-1186.

35. Ghannam S, Pene J, Torcy-Moquet G, Jorgensen C, Yssel H: Mesenchymal stem cells inhibit human Th17 cell differentiation and function and induce a T regulatory cell phenotype. J Immuno/ 2010, 185:302-312.

36. Darlington PJ, Boivin MN, Renoux C, Francois M, Galipeau J, Freedman MS, Atkins HL, Cohen JA, Solchaga L, Bar-Or A: Reciprocal Th1 and Th17 regulation by mesenchymal stem cells: implication for multiple sclerosis. Ann Neurol 2010, 68:540-545.

37. Freedman MS, Bar-Or A, Atkins HL, Karussis D, Frassoni F, Lazarus H, Scolding $\mathrm{N}$, Slavin S, Le Blanc K, Uccelli A: The therapeutic potential of mesenchymal stem cell transplantation as a treatment for multiple sclerosis: consensus report of the International MSCT Study Group. Mult Scler 2010, 16:503-510

38. Uccelli A, Laroni A, Freedman MS: Mesenchymal stem cells for the treatment of multiple sclerosis and other neurological diseases. Lancet Neurol 2011, 10:649-656.

doi:10.1186/scrt94

Cite this article as: Morando S, et al.: The therapeutic effect of mesenchymal stem cell transplantation in experimental autoimmune encephalomyelitis is mediated by peripheral and central mechanisms. Stem Cell Research \& Therapy 2012, 3:3. 